\title{
Properties of Polysiloxane Coated Borosilicate Lining Blocks
}

\author{
Jeongho Song and Ohsung Song ${ }^{\dagger}$ \\ Department of Materials Science and Engineering, University of Seoul, Seoul 02504, Korea
}

(Received August 29, 2017; Revised October 17, 2017; Accepted October 17, 2017)

\begin{abstract}
To improve the thermal resistance of a porous borosilicate lining block, we prepared and applied polysiloxane-fumed silica-ethanol slurry on top of the block and fired the coating layer using a torch for 5 minutes at $800^{\circ} \mathrm{C}$. We conducted magnified characterizations using a microscope and XRD analysis to observe phase transformations, and TGA-DTA analysis to determine the thermal resistance. Thermal characterizations showed improved heat resistance with relatively high polysiloxane content slurry. Cross-sectional optical microscope observation showed less melting near the surface and decreased pore formation area with higher polysiloxane content slurry. XRD analysis revealed that the block and coating layer were amorphous phases. TGA-DTA analysis showed an endothermic reaction at around $550^{\circ} \mathrm{C}$ as the polysiloxane in the coating layer reacted to form SiOC. Therefore, coating polysiloxane on a borosilicate block contributes to preventing the melting of the block at temperatures above $800^{\circ} \mathrm{C}$.
\end{abstract}

Key words : Thermal properties, Firing, Glass, Thermal applications

\section{Introduction}

B orosilicate glass is a type of glass with silica and boron trioxide as the main glass forming constituents. Porous borosilicate glass blocks are widely used in flue-gas desulfurization (FGD), which is a desulfurization process for thermoelectric power plants. ${ }^{1-3)}$ Porous blocks have continuously improved and are widely used in $150 \mathrm{~m}$ and $200 \mathrm{~m}$ class FGDs.

The block is attached to the inside of the chimney with a polymeric adhesive and protects the chimney's structure, which is made of concrete or steel, from deteriorating in heat and corroding in strong acidic gas. In other words, the block is used as a lining material that protects the chimney from the $100^{\circ} \mathrm{C}$ acidic gas that is a byproduct of the desulfurization process. ${ }^{4)}$

However, when an unexpected fire occurs in an FGD, an electrostatic filter module, or a heat storage module, during the operation of a thermoelectric power plant, the porous borosilicate blocks can be damaged in extreme fire conditions of $800^{\circ} \mathrm{C}$ for a period of 20 minutes. In case of such a fire, the borosilicate blocks can crack due to thermal expansion or the surface of the block can melt, making the block inoperable.

If the crack propagates in the z-axis direction in normal operating conditions, the block is damaged and the chimney's structure is also damaged due to the continuous heat and strong acidic gas. Thus, there is a need to suppress crack formation and propagation in blocks and to extend the

Corresponding author: Ohsung Song

E-mail : songos@uos.ac.kr

Tel : +82-2-6490-2410 Fax : +82-2-6490-2404 block service life. Accordingly, there is a need to develop a coating material with high heat resistance that can reduce damage from fire.

Polysiloxane has a continuous $\mathrm{R}_{1}-\mathrm{Si}-\mathrm{O}-\mathrm{R}_{2}$ siloxane chain, in which $\mathrm{R}_{1}$ and $\mathrm{R}_{2}$ can be $\mathrm{H}, \mathrm{CH}_{3}, \mathrm{C}_{2} \mathrm{H}_{5}, \mathrm{C}_{6} \mathrm{H}_{5}, \mathrm{CH}_{2}-\mathrm{CH}$ or $\mathrm{OH}$; polysiloxane is often referred to as silicone. ${ }^{5)}$ Compared to other polymeric materials, polysiloxane has excellent thermal and chemical resistant properties. Therefore, it is widely used as a sealant, insulator, and coating on glass material. ${ }^{67)}$ In addition, Moysan et al. ${ }^{8)}$ have reported that polysiloxane can be easily converted to SiOC ceramic by thermal treatment, which implies that the base material(borosilicate) can be protected in a fire situation due to the endothermic reaction in forming SiOC.

On the other hand, fumed silica is used as an additive to enhance the density and strength of porous glass. Lee et al. ${ }^{9)}$ used waste glass, clay, and hollow micro-spheres as starting materials and fumed silica as additive, and obtained a higher density of $1.47 \mathrm{~g} / \mathrm{cm}^{3}$ compared to previously reported $1.21 \sim 1.25 \mathrm{~g} / \mathrm{cm}^{3}$.

Coating a borosilicate block used as a lining block in desulfurization equipment with polysiloxane, which has an excellent heat resisting property, can improve the heat resistance of the borosilicate block and prevent the formation of cracks in a fire.

In this research, we coated commercially used borosilicate blocks with slurries having varying contents of polysiloxane and fumed silica. Then, we treated the coated blocks with fire and conducted optical and thermal characterizations.

\section{Experimental Procedure}

We prepared a porous borosilicate block with 8.8 wt\% 


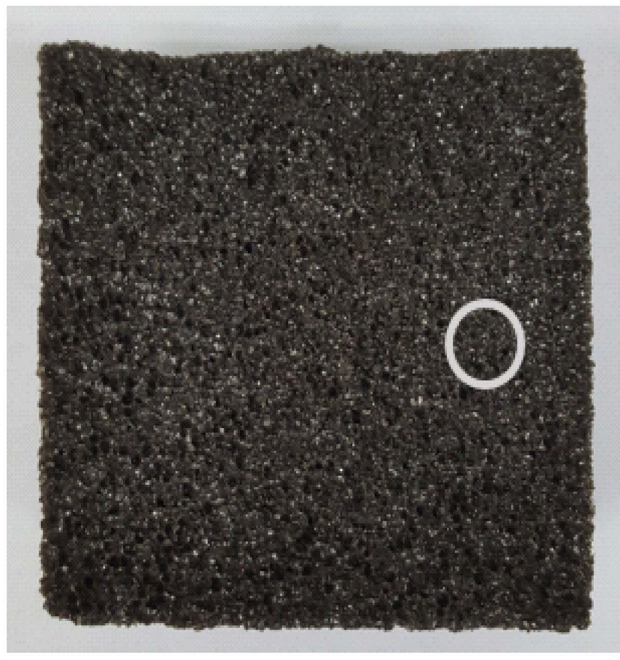

(a)

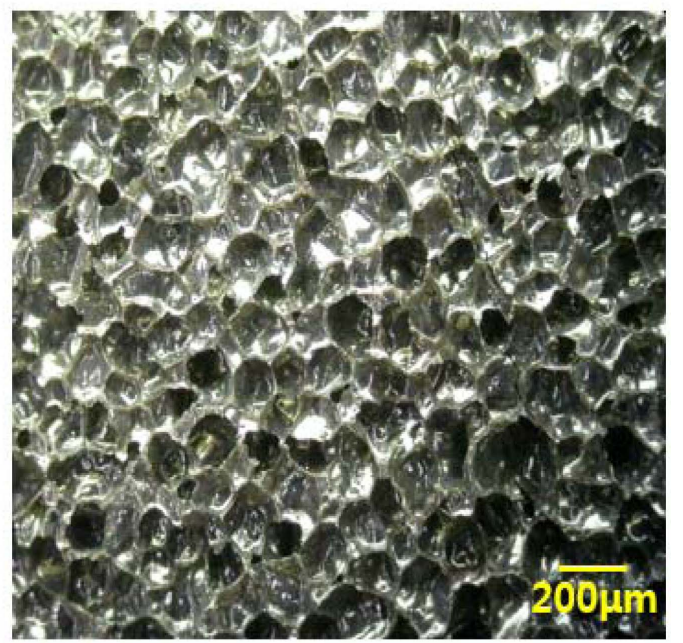

(b)

Fig. 1. (a) Macro and (b) magnified images of a borosilicate lining block.

Table 1. Batch Composition (wt\%)

\begin{tabular}{ccccc}
\hline $\begin{array}{c}\text { Sample } \\
\text { name }\end{array}$ & polysiloxane & $\begin{array}{c}\text { fumed } \\
\text { silica }\end{array}$ & ethanol & total \\
\hline $\mathrm{S} 1$ & 18 & 10 & 72 & 100 \\
$\mathrm{~S} 2$ & 21.88 & 9.38 & 68.74 & 100 \\
\hline
\end{tabular}

$\mathrm{B}_{2} \mathrm{O}_{3}$ (CLC company). The composition of the borosilicate block was 68.5 wt $\% \mathrm{SiO}_{2}-9.21$ wt $\% \mathrm{Na}_{2} \mathrm{O}-1.93$ wt $\% \mathrm{CaO}-8.77$ wt $\% \mathrm{~B}_{2} \mathrm{O}_{3}-0.82$ wt\% $\mathrm{K}_{2} \mathrm{O}-10.77$ wt\% others. The block was fabricated by adding a pore-forming agent to $\mathrm{SiO}_{2}$ particles. We prepared a plurality of samples with $100 \times 100 \times 35 \mathrm{~mm}$ dimensions (length $\times$ width $\times$ height).

Figure 1 shows images of the porous borosilicate block. Fig. 1(a) is a macro-image showing a black and glassy surface. Fig. 1(b) is a magnified image of the section circled in Fig. 1(a). The block was porous; the average pore size was approximately $107 \mu \mathrm{m} .8 \mu \mathrm{m}$-thick walls separated each pore so that the pores had closed structures; this structure yields excellent heat-resisting and anti-oxidant properties.

As shown in Table 1, we prepared two polysiloxane/fumed silica/ethanol slurries with different polysiloxane contents. Each slurry was placed in a $250 \mathrm{ml}$ mixing container; we milled each slurry using alumina-balls at $250 \mathrm{rpm}$ for $24 \mathrm{~h}$. Then, using a brush, each slurry was uniformly applied on top of a borosilicate block at approximately $200^{\circ} \mathrm{C}$ thickness; the blocks were dried for $6 \mathrm{~h}$ at $60^{\circ} \mathrm{C}$.

Figure 2 is an illustration of a heating module for a borosilicate block. To simulate an incident of a fire, we used a butane-gas torch and heated the polysiloxane coated-surface of the borosilicate block for 5 minutes at $800^{\circ} \mathrm{C}$. While heating, we shielded the heating source and the borosilicate block with fire-resistant blocks to avoid loss of heat.

The temperature during the heating was measured at 10seconds intervals using a two-channel thermometer with

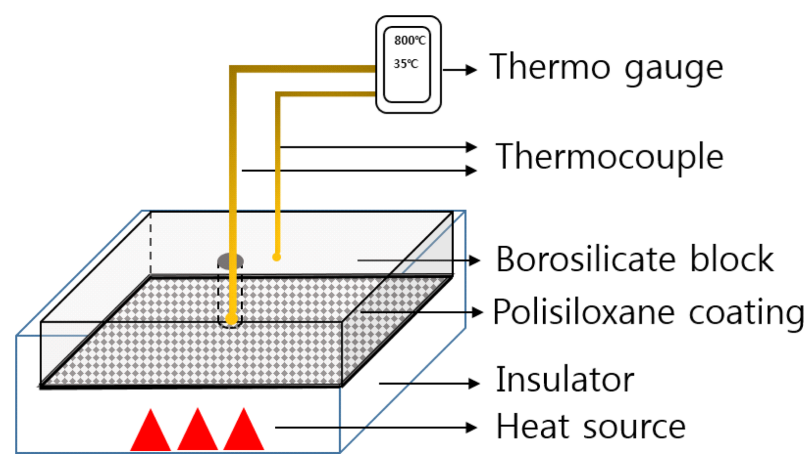

Fig. 2. Illustration of heating module for borosilicate block.

two thermocouples capable of measuring temperatures up to $1000^{\circ} \mathrm{C}$. The first sensor was located at $5 \mathrm{~mm}$ from the bottom of the borosilicate block inside the shielding through a hole; the second sensor was placed on the top surface of the block, at a point where the heating source cannot come into contact with it.

To observe the block's surface and the size of pores at the surface after the firing treatment, we used an optical microscope (GIA Instruments, 815000) with a digital camera (Nikon, Coolpix4500) attached to it.

To observe any phase transformation arising from polysiloxane coating or firing treatment, we employed X-ray diffraction equipment (PANalytical, X'pert-pro). The X-ray source was $\mathrm{CuK} \alpha$ with wavelength of $1.5405 \AA$. The tube current was $40 \mathrm{~mA}$ and the acceleration voltage was $40 \mathrm{kV}$. The data was measured for $2 \theta$ ranging from 10 to $120^{\circ}$.

To observe the thermal properties and changes in melting point after coating the borosilicate blocks, we employed TGA-DTA equipment (Netzsch, STA409PC). Each sample was measured from 20 to $1000^{\circ} \mathrm{C}$ at $10^{\circ} \mathrm{C} / \mathrm{min}$ heating rate in atmosphere. 


\section{Results and Discussion}

Figure 3 shows optical images of a cross sectional surface of the polysiloxane-coated borosilicate blocks after the firing treatment. Fig. 3(a) is an image of the reference sample without polysiloxane coating. The lead line indicates the thickness of the melted area with which the heating source came into direct contact. The thickness of the melted area, measured from the surface, was approximately $243 \mu \mathrm{m}$; the average size of pores near the melted area was $117 \mu \mathrm{m}$.

Figure 3(b) shows an image of the block coated with S1 slurry (see Table 1). After the firing treatment, the thickness of the melted area was approximately $180 \mu \mathrm{m}$, which was a $25.9 \%$ decrease compared to the thickness of the reference sample. On the other hand, the average size of pores near the melted area was $113 \mu \mathrm{m}$, which was smaller than the pores shown in (a).

Figure 3(c) shows an image of the block coated with S2 slurry, for which the thickness of the melted area was 91 $\mu \mathrm{m}$. This was significantly less melting compared to the reference or the $\mathrm{S} 1$ slurry-coated samples. In addition, the size of pores near the melted area was $111 \mu \mathrm{m}$, which was smaller than that of the pores measured in the reference or $\mathrm{S} 1$ slurry-coated samples. When the block is coated with a higher content of polysiloxane, which undergoes pyrolysis and an endothermic reaction, this leads to less melting on the surface and decreased rearrangements of pores. Therefore, the polysiloxane layer contributes to the prevention of damage on the borosilicate block surface in case of fire.

Figure 4 is a graph showing temperature changes of the borosilicate blocks during firing treatment. The reference block without coating reached a maximum temperature of $800^{\circ} \mathrm{C}$ in 60 seconds and maintained its temperature within the margin of error. On the other hand, the S1-slurry coated block rapidly reached $680^{\circ} \mathrm{C}$ (in 100 seconds), but took about 320 additional seconds to reach the maximum temperature of $800^{\circ} \mathrm{C}$. The polysiloxane coating and the resulting heat resistance slowed the heating rate.

The S2 slurry-coated sample took approximately 340 seconds to reach the maximum temperature. The heating rate

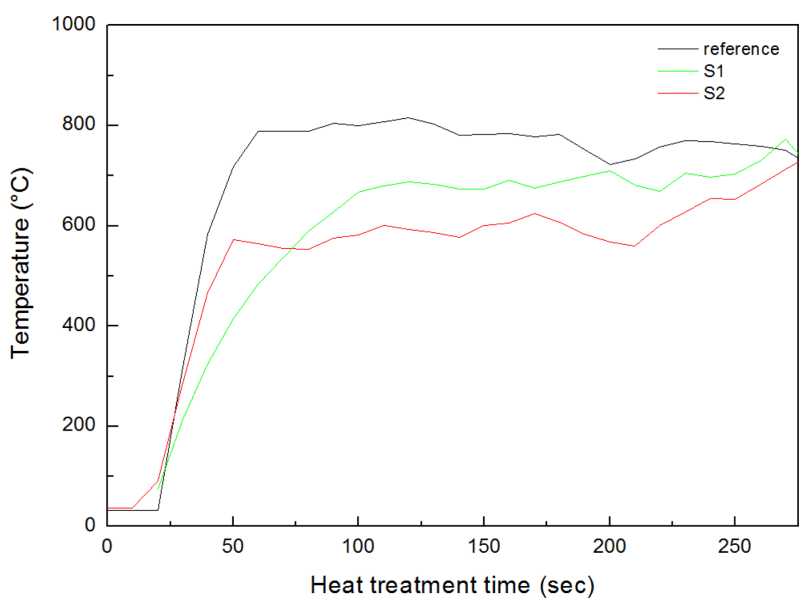

Fig. 4. Temperature changes of borosilicate blocks during firing treatment.

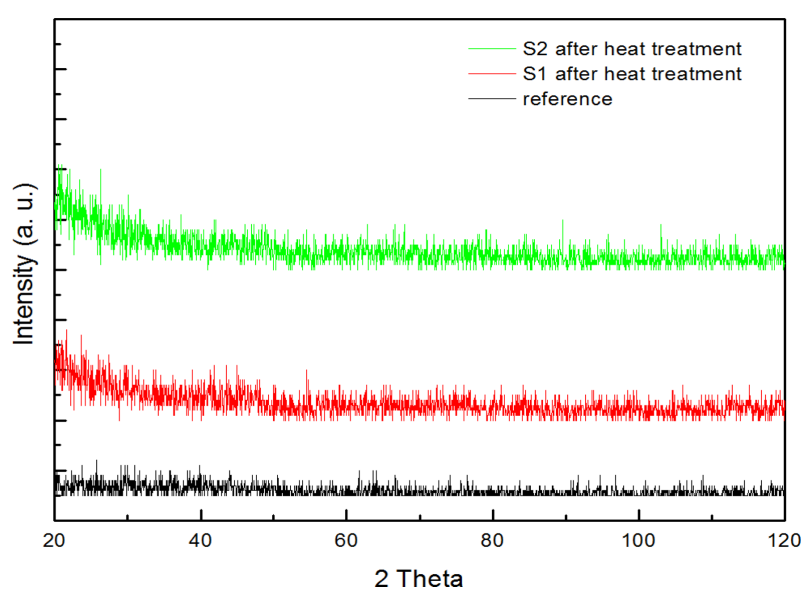

Fig. 5. XRD patterns of the reference, the S-1 coated, and the S-2 coated lining blocks.

for the S2 slurry-coated sample was lower and, therefore, this result confirmed that heat resistance improves as polysiloxane content increases.

When a coating layer is formed, the endothermic reaction arising from the pyrolysis of polysiloxane yields a tempera-

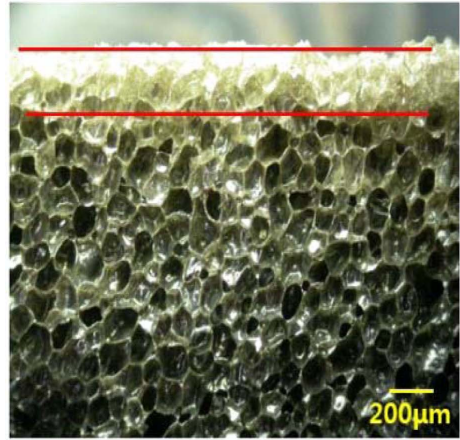

(a)

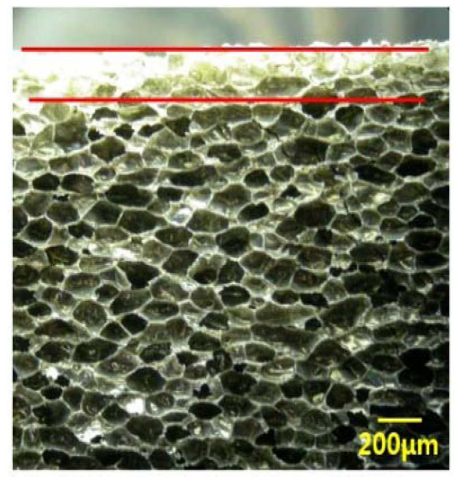

(b)

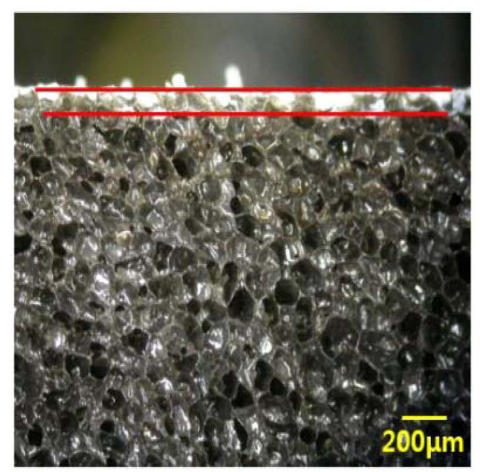

(c)

Fig. 3. Cross-sectional microscope images of (a) the reference, (b) the S1-coated, and (c) the S2-coated lining blocks after firing treatment. 
ture gradient, which leads to a heating rate lower than that for the reference block.

Figure 5 shows XRD patterns of the reference, S1 slurrycoated, and S2 slurry-coated blocks. All blocks were in amorphous phase without showing a clear peak within the $20 \sim 120^{\circ} \mathrm{C}$ measurement range, regardless of the firing treatment. This result shows that the blocks used in this experiment, including the product of lower polysiloxane reaction, which is a major component of the coating layer, and fumed-silica, were all in amorphous phase. Harshe et $a l .{ }^{10)}$ have reported a successful synthesis of bulk SiOC using polysiloxane as starting materials with heat treat-
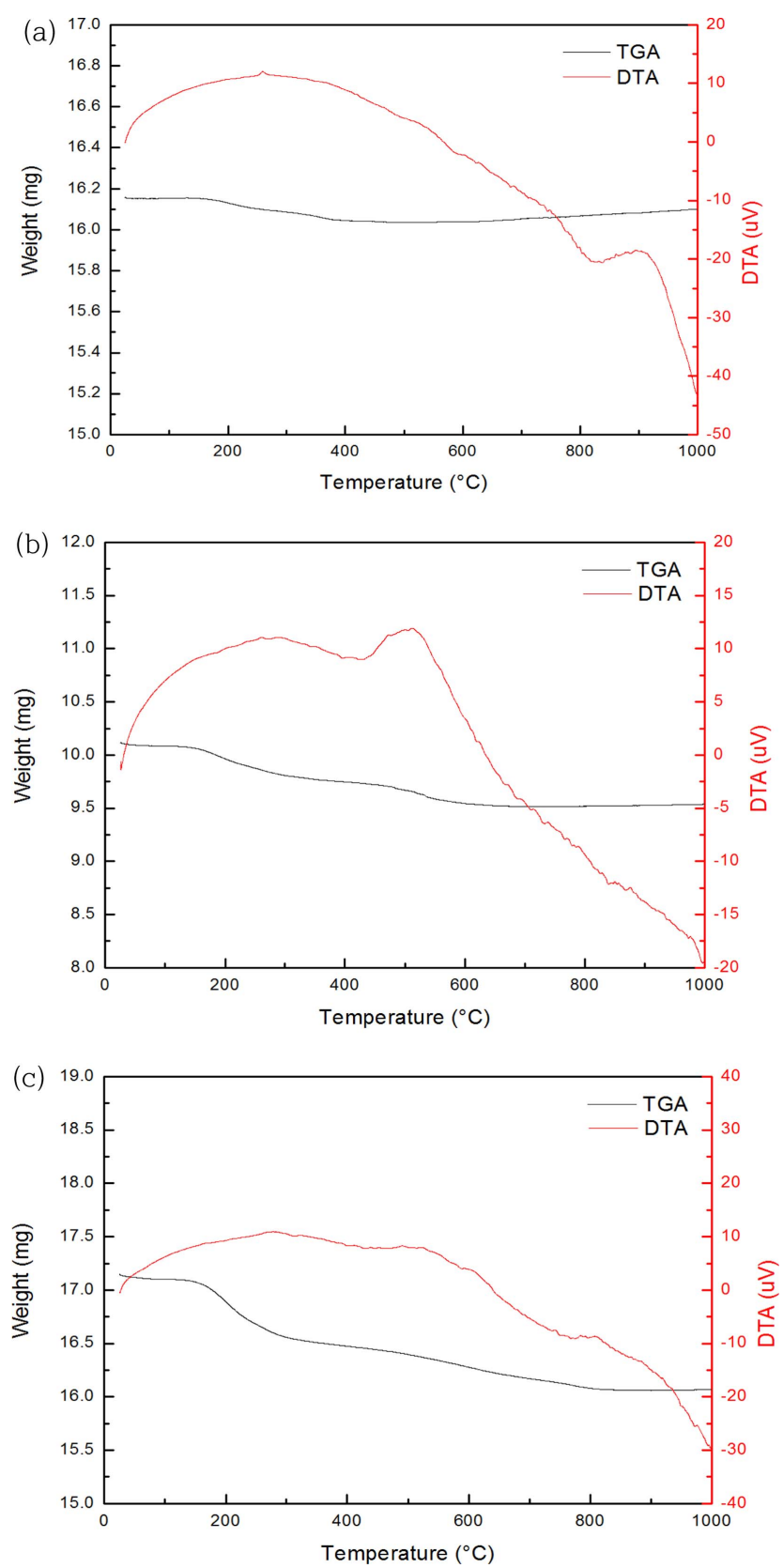

Fig. 6. TGA-DTA curves of (a) the reference, (b) the S1coated, and (c) the S2-coated lining blocks. ment at $700^{\circ} \mathrm{C}$. Kim et al. ${ }^{11)}$ have reported the formation of amorphous SiOC from the pyrolysis of polysiloxane.

Figure 6 shows TGA-DTA curves of the reference, S1coated, and S2-coated blocks. Fig. 6(a) shows the results for the reference block. The change in weight as observed in the TGA graph was within the margin of error, and is thus insignificant. On the other hand, the DTA graph showed a weak heat absorption at $258.57^{\circ} \mathrm{C}$ due to the evaporation of residual moisture in the block. Then, a strong heat absorption peak at $838.53^{\circ} \mathrm{C}$ was observed after a continuous decrease.

We determined that the strong peak was due to the endothermic reaction of the solid borosilicate block undergoing a phase transformation to liquid state at its glass transition temperature. Essentially, this change is due to melting, which means that the block will melt in case of a fire; thus, this result implies a limitation to the heat resistance.

Figure 6(b) is a TGA-DTA curve of the S1 slurry-coated block. The TGA graph shows a decrease in weight at around $170 \sim 180^{\circ} \mathrm{C}$. We determined that this decrease was due to the loss of moisture and functional groups such as alkyl groups after crosslinking. ${ }^{12)}$ Also, the DTA curve shows a heat absorption peak at around $550^{\circ} \mathrm{C}$ that was due to the endothermic reaction of polysiloxane pyrolysis, polysiloxane $\rightarrow \mathrm{SiOC}+\mathrm{C}$, and the corresponding heat absorption. ${ }^{13)}$

On the other hand, we did not observe the strong peak that was observed in Fig. 6(a). We determined, as with the results obtained by optical microscope, that polysiloxane coating contributes to the prevention of damage on the borosilicate block.

Figure 6(c) shows a TGA-DTA curve of the S2-coated borosilicate block. As with Fig. 6(b), we did not observe any borosilicate melting reaction except for partial heat absorption at around $550^{\circ} \mathrm{C}$. The TGA graph shows a decrease in weight at around $180^{\circ} \mathrm{C}$, which was due to the removal of functional groups in polysiloxane.

As with the optical microscope and firing treatment analysis, this result revealed that the polysiloxane coating on the borosilicate block contributes to the prevention of borosilicate melting. Thus, the polysiloxane layer contributes to the prevention of damage on the borosilicate block in a fire.

\section{Conclusions}

We coated porous borosilicate blocks, used as lining blocks in a desulfurization system, with slurries with varying polysiloxane contents and analyzed the properties of the resulting borosilicate block. Optical analysis using a microscope showed pore size increase as the lining block was exposed to heat and less melting when a slurry with high polysiloxanecontent was applied. The temperature measurement confirmed that heat resistance improved when polysiloxane was applied because of the polysiloxane endothermic reaction and the corresponding heat absorption. XRD analysis showed no clear peaks, which indicated that the block was composed of amorphous elements. TGA-DTA analysis showed 
improved heat resistance after the heat-treatment due to heat absorption effect. Thus, coating a borosilicate block with polysiloxane slurry contributes to damage prevention in cases of fire.

\section{REFERENCES}

1. S. W. Youn, Y. L. Shin, and C. G. Kang, "A Study on the Nano-Deformation Behaviors of Single Crystal Silicon and Amorphous Borosilicate Considering the Mechanochemical Reaction," Trans. Mater. Process., 12 [7] 623-30 (2003).

2. S. Zhao, Y. Zhao, Y. Han, C. An, J. Wei, and Y. Yao, "Prevention of Stack Corrosion under Wet Flue Gas Desulfurization Conditions in a Coal-Fired Power Plant: Performance Analysis and Comparative Study," Environ. Syst. Res., 5 [1] 21-31 (2016).

3. I. H. Back, H. B. Lim, and C. Y. Kim, "Mechanism of Removal of $\mathrm{Cr}(\mathrm{VI})$ Ions from Solution by Borosilicate Glasses Containing Alkaline Earth Oxides," J. Korean Ceram. Soc., 48 [3] 222-27 (2011).

4. Y. S. Song, H. O. Kwan, and N. I. Jho, "Evaluation of the Organic Linings at Gas Desulfurization System," J. Kor. Soc. Precis. Eng., 29 [11] 1178-82 (2012).

5. B. V. Manoj Kumar and Y. W. Kim, "Processing of Polysiloxane-Derived Porous Ceramics: A Review," Sci. Technol. Adv. Mater., 11 [4] 044303-18 (2010).
6. P. Colombo, G. Mera, R. Riedel, and G. D. Soraru, "Polymer-Derived Ceramics: 40 Years of Research and Innovation in Advanced Ceramics," J. Am. Ceram. Soc., 93 [7] 1805-37 (2010)

7. M. Narsawa, "Silicone Resin Applications for Ceramic Precursors and Composites," Materials, 3 [6] 3518-36 (2010).

8. C. Moysan, R. Riedel, R. Harshe, T. Rouxel, and F. Augereau, "Mechanical Characterization of a Polysiloxane-Derived SiOC Glass," J. Eur. Ceram. Soc., 27 [1] 397-403 (2007).

9. Y. I. Lee, J. H. Eom, Y. W. Kim, and I. H. Song, "Effect of Additive Composition on Flexural Strength of CulletLosses Tile Bodies," J. Korean Ceram. Soc., 50 [6] 416-22 (2013).

10. R. Harshe, C. Balan, and R. Riedel, "Amorphous Si(Al)OC Ceramic from Polysiloxanes: Bulk Ceramic Processing, Crystallization Behavior and Applications," J. Eur. Ceram. Soc., 24 [12] 3471-82 (2004).

11. K. J. Kim, J. H. Eom, Y. W. Kim, and W. S. Seo, "Electrical Conductivity of Dense, Bulk Silicon-Oxycarbide Ceramics," J. Eur. Ceram. Soc., 35 [5] 1355-60 (2015).

12. D. W. Kim, Synthesis of Porous SiC Ceramics from a Polysiloxane (in Korean), pp. 28-30, in M. S. Thesis, Korea Maritime and Ocean University, Busan, 2007.

13. Y. W. Kim, D. H. Jang, J. H. Eom, I. H. Song, and H. D. Kim, "Processing of Polymer-Derived Microcellular Ceramics Containing Reactive Fillers," Mater. Sci. Forum, 534536 989-92 (2007). 